\title{
CONCURRENT SOLUTION AND ADSORPTION OF HYDROCARBONS IN GAS CHROMATOGRAPHIC COLUMNS PACKED WITH DIFFERENT LOADINGS OF 3-METHYLSYDNONE ON CHROMOSORB P
}

\author{
ADSORCION Y DISOLUCION SIMULTANEA DE HIDROCARBUROS EN COLUMNAS DE \\ CROMATOGRAFIA GASEOSA RELLENAS CON DIFERENTES CARGAS \\ DE 3-METILSYDNONA SOBRE CHROMOSORB P
}

R.C. Castells ${ }^{1}$, L.M. Romero ${ }^{2}$, A.M. Nardillo ${ }^{3}$

\begin{abstract}
SUMMARY
Thermodynamic properties of solution in 3-methylsydnone (3MS) and of adsorption at the nitrogen/3MS interface were gas chromatographically measured for a group of fifteen hydrocarbons at infinite dilution conditions. Retention volumes were measured at five temperatures within the range $37-52^{\circ} \mathrm{C}$ in six columns containing different loadings of $3 M S$ on Chromosorb $P A W$. Partition and adsorption coefficients were calculated and from their temperature dependence the corresponding enthalpies were obtained, although with considerable error; infinite dilution activity coefficients of the hydrocarbons in the bulk and in the surface phases demonstrated an strong correlation. Bulk activity coefficients in $3 M S$ were very much smaller than those previously measured for the same solutes in formamide (FA) and in ethyleneglycol (EG), and were also smaller than what could be predicted on account of $3 M S$ cohesive energy density as estimated from the quotient $\sigma / v^{1 / 3}(\sigma$. surface tension; $v$ : molor volume). There was not such a large difference between the surface activity coefficients in the three solvents; furthermore, the quotients (surface activity coefficient/bulk activity coefficient) for a given solute in $3 M S$ were twice as large as in FA and about three times larger than in EG. These results make evident the difficulties inherent in the prediction of surface phase properties from those in the bulk, and cast doubts on the pertinency of employing the surface tension to compare cohesive energy densities of polar solvents with important chemical differences.
\end{abstract}

Keywords: 3-methylsydnone; adsorption; solution activity coefficients; surface activity coefficients; gas chromatography; chromatography thermodynamics .

\section{INTRODUCTION}

3-Methylsydnone (3MS) is a polar solvent with some interesting properties; conspicuous among these are the large values of its dielectric constant and of its dipole

\footnotetext{
${ }^{1}$ Miembro de la Carrera del Investigador del CONICET; Profesor Trular, UNLP

${ }^{2}$ División de Quimica Analitica, Facuthad de Ciencias Exacas, Universidad Nacional de La Plata

${ }^{3}$ Miembro de la Carrera del Investigador del CONICET; Profesor Asociado, UNLP
} 
moment. Some of its physical properties are given in Table 1 together with the corresponding values for formamide (FA) and ethyleneglycol (EG), two solvents that shall be compared with 3MS in the present paper. While FA and EG are highly associated liquids, 3MS is aprotic and the value of its Kirkwood $g$ factor is 1.1 [1], indicating a random distribution of the molecular dipoles. However the cohesive energy density (c.e.d) of $3 \mathrm{MS}$ measured by the quotient $\sigma / v^{1 / 3}$, as proposed by Gordon [2], is apparently very high and intermediate between those of FA and EG.

\section{Table 1}

\section{Physical Properties of Solvents}

\begin{tabular}{|c|c|c|c|}
\hline & $\mathrm{EG}, 25^{\circ} \mathrm{C}$ & $\mathrm{FA}, 25^{\circ} \mathrm{C}$ & $3 \mathrm{MS}, 40^{\circ} \mathrm{C}$ \\
\hline Dielectric Constant, $\varepsilon$ & $37.7^{\circ}$ & 105. & $144^{c}$ \\
\hline Dipole Moment, $\mu$ (D) & $2.28^{\circ}$ & $3.73^{2}$ & $7.3^{d}$ \\
\hline $\begin{array}{l}\text { Surface Tension, } \sigma \\
(\mathrm{dyn} / \mathrm{cm})\end{array}$ & $46^{b}$ & $57.9^{b}$ & $57 .^{\mathrm{C}}$ \\
\hline Refractive Index, $\mathrm{n}^{\mathrm{D}}$ & $1.4306^{b}$ & $1.4468^{b}$ & $1.5150^{c}$ \\
\hline Viscosity, $\eta(c p)$ & $16.2^{\circ}$ & $3.30^{\star}$ & $5.50^{c}$ \\
\hline $\begin{array}{l}\text { Molar Volume, } v \\
\left(\mathrm{~cm}^{3} / \mathrm{mol}\right)\end{array}$ & $55.92^{b}$ & $39.89^{b}$ & $76.49^{c}$ \\
\hline$\sigma / v^{1 / 3}\left(\mathrm{dyn} / \mathrm{cm}^{2}\right)$ & 12.0 & 16.9 & 13.4 \\
\hline
\end{tabular}

On account of its high dielectric constant and c.e.d., 3MS was a good candidate to promote amphiphilic aggregation. But Evans and collaborators [3] were unable to detect formation of micelles in this solvent, a fact that these authors associated with the absence of nydrogen bonding in 3MS. This made the measurement of free energies of solution of hydrocarbons in $3 \mathrm{MS}$ interesting since, as Evans pointed out, they are intimately related to the driving force for surfactants aggregation. This interest was reinforced by the lack of information about the solvent properties of 3MS.

Gas chromatography, using 3MS as the stationary phase, offers a series of advantages for these measurements. In the first place because chromatographic measurements can be effectively done at infinite dilution of the solute in the stationary phase. In the second place because a considerable gas-liquid interface is generated when the stationary phase is coated on a porous solid; for a polar liquid like 3MS, in which the hydrocarbons shall display important positive deviations from the ideal solution behavior, a mixed retention mechanism can be predicted: partition in the bulk liquid and adsorption on the gas-liquid interface [4-6]. Using adequate conditions the thermodynamic parameters characteristic of both processes can be simultaneously determined. Finally the measurements can be performed over a range of temperatures, and partition and adsorption enthalpies may be evaluated [7], although with considerable uncertainties because of the indirect nature of the calculation 
The retention behavior of fifteen hydrocarbons representative of different families was measured in the present work at five temperatures equally spaced within the range $37-52^{\circ} \mathrm{C}$, in six columns containing different concentrations of $3 \mathrm{MS}$ in their packings. Experimental results are treated according with well established theoretical chromatographic principles.

\section{MATERIALS AND METHODS}

3MS was synthesized from N-methylglycine by the method of Vasil'eva and Yashunskii [8]. N-nitroso-N-methylglycine was extracted with ether, during $36 \mathrm{~h}$, in a liquid-liquid extraction apparatus; the extract was dried with magnesium sulfate and the ether was vacuum distilled. The intermediate was then reacted with acetic anhydride $(5.5$ moles per mole of Nmethylglycine) for ten days in the dark at room temperature. Excess acetic anhydride was removed under vacuum using toluene to remove the last traces, and 3MS was distilled twice under vacuum $\left(145^{\circ} \mathrm{C} / 0.25 \mathrm{Torr}\right)$, a $20 \mathrm{~cm}$ Vigreaux column being intercalated in the second opportunity. The product thus obtained was lightly yellow, melted at about $36^{\circ} \mathrm{C}$ and its IR spectrum was coincident with that appearing in ref. 3 . Hydrocarbon solutes of different origins, all of them more than $99 \%$ pure, were used as received; their names can be read in Table 2.

Table 2

Thermodynamic functions of partition and adsorption of hydrocarbons at infinite dilution in 3-Methylsydnone at $40^{\circ} \mathrm{C}$

$\begin{array}{lcccc}\text { SOLUTE } & \mathrm{K}_{\mathrm{L}} \pm \sigma\left(\mathrm{K}_{\mathrm{L}}\right) & \begin{array}{c}-\Delta \mathrm{H}_{\mathrm{L}}^{\circ} \\ (\mathrm{KJ} / \mathrm{mol})\end{array} & \begin{array}{c}\mathrm{K}_{\mathrm{A}} \pm \sigma\left(\mathrm{K}_{\mathrm{A}}\right) \\ \left(\mathrm{x} 10^{4} \mathrm{~cm}\right)\end{array} & \begin{array}{c}-\Delta \mathrm{H}_{\mathrm{A}}^{\circ} \\ (\mathrm{KJ} / \mathrm{mol})\end{array} \\ \text { n-Heptane } & 9.98 \pm 0.22 & 25.7 \pm 2.6 & 3.46 \pm 0.01 & 33.9 \pm 1.3 \\ \text { n-Octane } & 19.8 \pm 0.47 & 30.4 \pm 3.5 & 9.11 \pm 0.02 & 38.8 \pm 1.7 \\ \text { n-Nonane } & 41.3 \pm 2.02 & 37.8 \pm 7.6 & 24.0 \pm 0.11 & 42.8 \pm 2.3 \\ \text { n-Decane } & 108.12 .0 & 44.9 \pm 18.5 & 61.0 \pm 0.63 & 46.8 \pm 3.0 \\ \text { 2,2,4-Trimethylpentane } & 9.75 \pm 0.39 & 29.4 \pm 4.4 & 4.43 \pm 0.02 & 33.5 \pm 1.3 \\ \text { Methylcyclohexane } & 21.5 \pm 0.20 & 21.9 \pm 1.3 & 2.58 \pm 0.01 & 31.6 \pm 1.1 \\ \text { Ethylcyclohexane } & 46.0 \pm 0.96 & 27.0 \pm 2.7 & 6.66 \pm 0.05 & 34.8 \pm 1.9 \\ \text { 1-Heptene } & 18.6 \pm 0.30 & 23.7 \pm 2.0 & 4.02 \pm 0.01 & 35.0 \pm 1.3 \\ \text { 1-Octene } & 35.4 \pm 0.90 & 29.1 \pm 3.9 & 10.7 \pm 0.05 & 38.8 \pm 2.2 \\ \text { 1-Nonene } & 73.3 \pm 2.40 & 39.5 \pm 5.7 & 27.6 \pm 0.12 & 42.3 \pm 2.2 \\ \text { Benzene } & 237 . \pm 0.83 & 29.3 \pm 1.2 & 2.61 \pm 0.04 & 30.3 \pm 2.6 \\ \text { Toluene } & 455 . \pm 1.95 & 32.4 \pm 1.2 & 7.86 \pm 0.10 & 36.4 \pm 2.3 \\ \text { Ethylbenzene } & 746 . \pm 4.92 & 34.5 \pm 1.8 & 20.2 \pm 0.26 & 40.4 \pm 2.9 \\ \text { m-Xylene } & 875 . \pm 6.23 & 35.5 \pm 2.1 & 22.7 \pm 0.32 & 40.9 \pm 3.4 \\ \text { p-Xylene } & 829 \pm 5.25 & 35.3 \pm 2.0 & 22.1 \pm 0.27 & 41.2 \pm 3.1\end{array}$

Chromatographic packings were prepared by coating 3MS on Chromosorb $\mathrm{P}$ AW $60 / 80$ (Johns-Manville pink diatomaceous earth support) in a rotary evaporator, under a nitrogen stream and gentle heating, using chloroform as the volatile solvent. Six different packings, containing $5.11_{3}, 7.02_{6}, 9.05_{1}, 11.53_{8}, 15.74_{6}$ and $19.51_{0} \%$ by weight of $3 \mathrm{MS}$ were 
prepared. Coated supports were packed into $0.53 \mathrm{~cm}$ I.D. stainless steel tubes, 0.50 or $1.0 \mathrm{~m}$ in length.

Column temperature was controlled to better than $\pm 0.05^{\circ} \mathrm{C}$ by immersion in a water bath. Nitrogen was used as carrier gas; it was successively passed through a molecular sieves trap (Davidson 5A), a Brooks 8606 pressure regulator, a Brooks 8743 flow controller and a 2 $\mathrm{m} \times 1 / 8$ in O.D. coiled copper tube immersed in the column bath. Inlet pressures were measured with a mercury manometer at a point between the copper coil and a Swagelock 1/4 in s.s. "T"; one branch of the latter was provided with a septum through which solute vapors were injected by means of Hamilton microsyringes; the column was connected to the remaining branch. Detection was performed with a Hewlett-Packard 5750 FID and electrometer whose signals were fed to a Hewlett-Packard 3396A integrator.

Sample sizes were of the smallest size compatible with instrumental noise (about $10 \mathrm{nmol}$ ); solute vapors and a small methane sample were simultaneously injected, and adjusted retention times were measured to $10^{-3} \mathrm{~min}$ between the maxima of the solute and the methane peaks. Specific retention volumes $\left(V_{g}^{o}\right)$ and net retention volumes per gram of packing $\left(V_{N}^{\circ}\right)$ were calculated in the usual form [9] from adjusted retention times and values of the experimental variables.

\section{RESULTS AND DISCUSSION}

Specific retention volumes measured in a given column were fitted to the equation

$$
\text { in } V_{g}^{\circ}=-\Delta H_{S}^{\circ} / R T+\text { constant }
$$

where $\Delta H_{s}^{\circ}$, the heat of sorption, may signify different things depending on the retention mechanism(s). Differences between $V_{g}^{\circ}$ values calculated by means of Eq. (1) and experimental values were smaller than $0.3 \%$; interpolation was thus very accurate and data obtained in different columns at slightly different temperatures could be corrected to a common temperature to enable further elaboration of results. Within experimental error (between $\pm 1 \%$ and $\pm 4 \%$ at a $95 \%$ confidence level) the heats of sorption were found to be independent of stationary phase loading.

In Figure $1 V_{N}^{\circ}$ values at $43^{\circ} \mathrm{C}$ for a group of selected hydrocarbons, representative of different families, have been plotted against the percentage by weight of $3 \mathrm{MS}$ in the packing, w. There are notorious differences between the solutes and in none of the cases the retention can be explained exclusively in terms of solution in the stationary phase, since straight lines through the origin should be expected in that case; the existence of more than one retention mechanism is made evident. Conder et al. [5] proposed a model that takes realistically into account the most important possible contributions to solute retention; their model may be summarized in the equation

$$
V_{N}^{o}=K_{L} V_{L}+K_{A} A_{L}+K_{S} A_{S}
$$


where $\mathrm{K}_{\mathrm{L}}$ is the liquid-gas partition coefficient, $\mathrm{K}_{\mathrm{A}}$ and $\mathrm{K}_{\mathrm{S}}$ are the adsorption coefficients at the gas-liquid and at the liquid-solid interfaces, respectively, and $V_{L}, A_{L}$ and $A_{s}$ represent the stationary phase volume, the gas-liquid interfacial area and the solid-liquid interfacial area, all of them expressed per gram of packing. Adsorption on uncovered portions of the solid support, not included in Eq. (2), needs not to be considered when more than $2-3 \%$ by weight of a polar stationary phase is coated on the polar surface of Chromosorb $\mathrm{P}$, whose specific surface area is about $4 \mathrm{~m}^{2} \mathrm{~g}^{-1}$. Furthermore, it is highly improbable that $3 \mathrm{MS}$ molecules, highly polar and in enormous excess, might be displaced from their positions on the solid surface by hydrocarbon molecules. These considerations indicate that for the systems and experimental conditions of this work $\mathrm{K}_{\mathrm{L}}$ and $\mathrm{K}_{\mathrm{A}}$ can be evaluated by fitting $\mathrm{V}_{\mathrm{N}}^{\circ}$ to Eq. (2) with $\mathrm{K}_{\mathrm{S}}=0$.

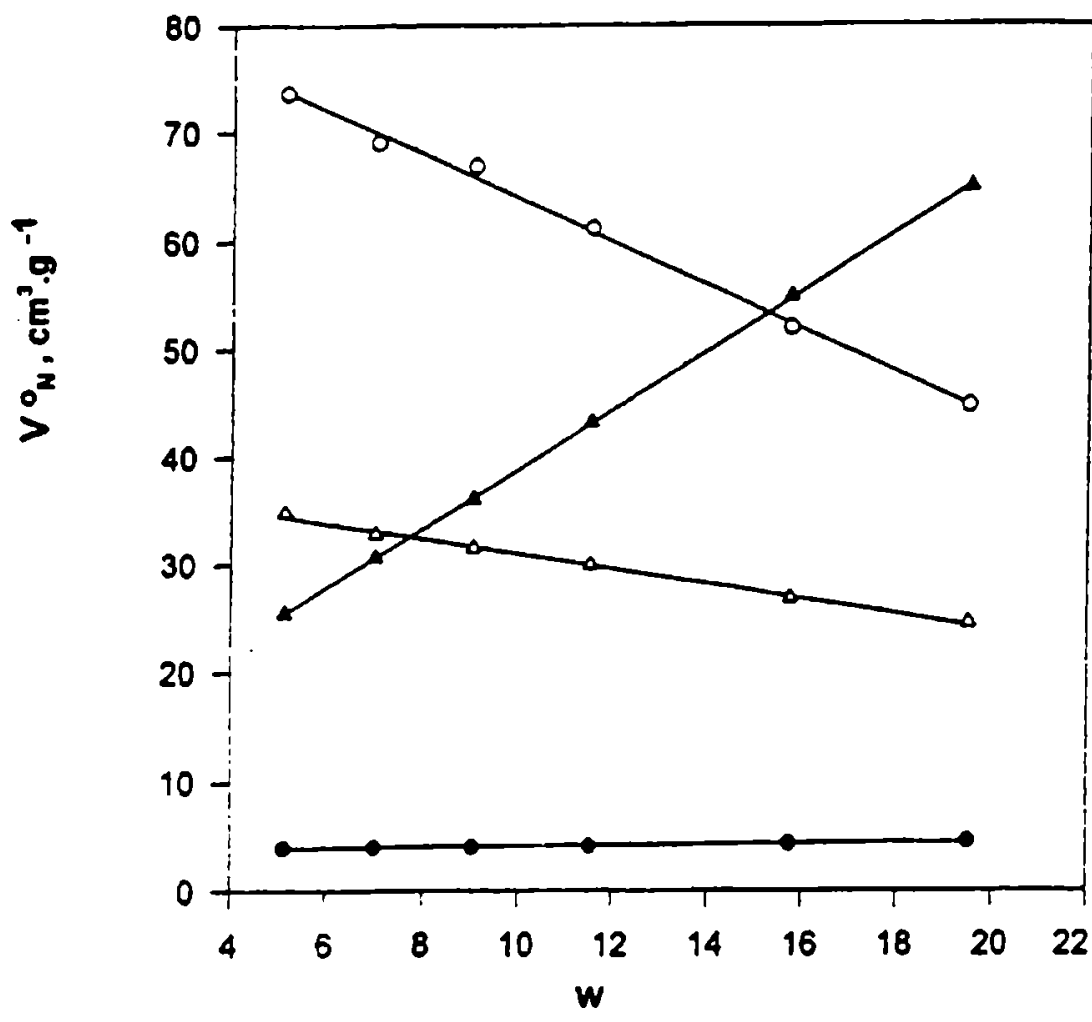

Fig. 1.- Retention volume per gram of packing at $43^{\circ} \mathrm{C}, V_{N}^{\circ}$, against percentage by weight of $3 \mathrm{MS}$ in the packing, $w$. $O:$ n-Decane; $\Delta$ : 1-nonene; : methylcycloherane; $\Delta$ : toluene.

In order to use the reduced form of Eq. (2) the areas $A_{L}$ remain to be evaluated; this was done by following the proposal of Martire et al. [10], i.e. combining statically measured values of $K_{L}$ and $K_{A}$ for benzene and cyclohexane in $\beta, \beta^{c}$-thiodipropionitrile (TDPN) with retention volumes obtained for both solutes in columns containing different loadings of TDPN on Chromosorb P and assuming that at the same loading of TDPN or 3MS calculated on a per volume basis both liquids have equal exposed surface areas. Thus obtained surface areas drop almost lineally with $\mathrm{w}$ for packings containing more than about $4 \mathrm{~mL}$ of stationary phase per $100 \mathrm{~g}$ of packing; this is why the plots of $\mathrm{V}_{\mathrm{N}}^{\circ}$ against $\mathrm{w}$ are straight lines with negative slopes for solutes whose retention is strongly adsorption dominated, as normal decane (see Figure 1).

Calculations performed by the same authors [10] indicate that the apparent liquid film thickness on Chromosorb $\mathrm{P}$ when $\mathrm{w}=5 \%$ is about $30 \mathrm{~nm}$, and $200 \mathrm{~nm}$ when $\mathrm{w}=20 \%$. A volume of $1.3 \times 10^{-22} \mathrm{~cm}^{3} /$ molecule can be calculated for $3 \mathrm{MS}$ in the liquid state at $40^{\circ} \mathrm{C}$. If it is assumed that each molecule moves freely within a spherical cell with diameter $\mathrm{d}$, a value of $\mathrm{d}=0.6 \mathrm{~nm}$ can be calculated; this means that a stationary phase film 50 molecules thick could be calculated for the more lightly loaded packing in the present work. It is difficult to ascertain if support influence can be felt at the gas-liquid interface of such a film, and what fraction of the liquid is under true bulk conditions. This is an old and unresolved discussion between 
chromatographers; probably the best answer is given by the results in Figure 1, that shows that $V_{N}^{o}$ values obtained with the lower loadings fall in line with those measured with the higher ones, for which films of up to 330 molecules can be calculated.

Values of $\mathrm{K}_{\mathrm{L}}$ (intercepts) and $\mathrm{K}_{\mathrm{A}}$ (slopes) were obtained from the linear regression of $V_{N}^{o} / V_{L}$ against $A_{L} / V_{L}$; the equation of $3 M S$ density versus temperature given by Lemire and Sears [1] was employed. Correlation coefficients were always larger than 0.999 , and in many cases larger than 0.9999 .

Standard enthalpies of solution were computed with the equation

$$
\Delta H_{L}^{0}=-R\left[\partial \ln K_{L} / \partial(1 / T)\right]-R T\left(1-\alpha_{1} T\right)
$$

where $\alpha_{1}$ is the thermal expansion coefficient of 3MS, computed by means of the equation of Lemire and Sears. $\Delta \mathrm{H}_{L}^{\circ}$ corresponds to the transfer of one mole of solute from an ideal vapor phase at a pressure of 1 atm to an hypothetical solution where it is at unitary molar fraction with behavior extrapolated from infinite dilution [11]. On applying Eq.(3) a constant enthalpy of solution through the experimental temperature range was assumed, and non-idealities of the vapor phase were neglected. Both assumptions are justified by the unavoidably large errors in the measurement of $\Delta \mathrm{H}_{\mathrm{L}}^{\circ}$ by combining data obtained in several columns.

Standard enthalpies of adsorption were calculated by means of the equation

$$
\Delta H_{A}^{\circ}=R\left[\partial \ln K_{A} / \partial(1 / T)\right]
$$

and correspond to the transfer of one mole of solute from the ideal vapor phase at 1 atm to an ideal adsorbed state where adsorbate molecules interact with the surface only [12]. Again, temperature independence of $\Delta \mathrm{H}_{A}^{\circ}$ and an ideal vapor phase was assumed in the calculations.

Solution and adsorption properties for the fifteen hydrocarbons in $3 \mathrm{MS}$ at $40^{\circ} \mathrm{C}$ were gathered in Table 2. Uncertainties given for $\mathrm{K}_{\mathrm{L}}$ and for $\mathrm{K}_{\mathrm{A}}$ are the standard deviations for the intercepts, $\sigma\left(\mathrm{K}_{\mathrm{L}}\right)$, and for the slopes, $\sigma\left(\mathrm{K}_{\mathrm{A}}\right)$, respectively, obtained in the regression of $V_{N}^{\circ} / V_{L}$ against $A_{L} / V_{L}$. The confidence ranges for $\Delta H_{L}^{\circ}$ and $\Delta H_{A}^{\circ}$ at the $95 \%$ level were calculated taking into consideration that two successive regressions are necessary to calculate the enthalpy values [7].

The percent contribution of adsorption to the retention volume for four representative hydrocarbons in the columns containing extreme $3 \mathrm{MS}$ loadings, calculated using $\mathrm{K}_{\mathrm{L}}$ and $\mathrm{K}_{\mathrm{A}}$ values, are given in Table 3 . In the first place these results give us an idea of the enormous errors that the neglect of adsorption would introduce in the study of the solution process; in the second, they explain the large errors made on computing $\Delta H_{L}^{\circ}$ for paraffins. In the case of n-decane, a solute whose percent adsorption retention is $95 \%$ at the $5.11_{3} \%$ loading and $70 \%$ at the $19.51_{0} \%$ loading, that error amounts to $41 \%$ of $\Delta H_{L}^{\circ}$

In order to investigate any correlation between solution and adsorption properties values of $\mathrm{K}_{\mathrm{A}}$ at $40^{\circ} \mathrm{C}$ have been plotted against those of $\mathrm{K}_{\mathrm{L}}$ in Figure 2. Points corresponding to solutes belonging to a given family fall on a common straight line, but there is not a general 
correlation involving hydrocarbons of different families. A similar behavior can be detected in the plot of $\Delta H_{A}^{\circ}$ against $\Delta H_{L}^{\circ}$ in Figure 3, although the trends are not so clear in this case as a consequence of the large errors involved in the measurement of the enthalpies.

Table 3

\section{Percent contribution of adsorption to the retention volume for extreme loadings at $45^{\circ} \mathrm{C}$}

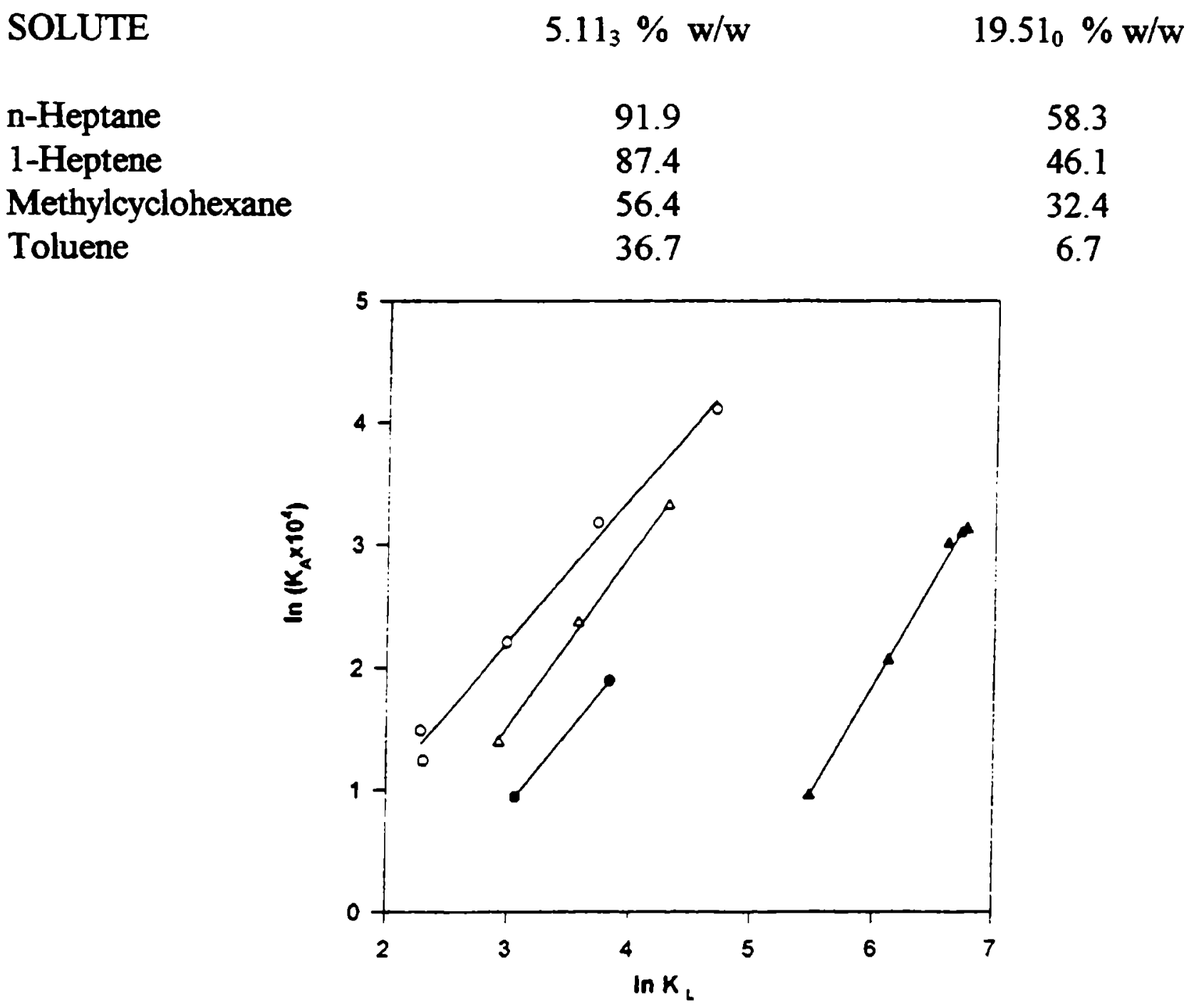

Fig. 2.- Relationship between adsoption and partition coeficients at $40{ }^{\circ} \mathrm{C}$ O: Allomes; $\Delta$ : 1-allcenes; : cycloallomes; $\Delta$ : aromatica

Bulk phase activity coefficients at infinite dilution, $\gamma_{2}^{b, \infty}$, were calculated by means of the equation

$$
\gamma_{2}^{b_{0}, \infty}=R T / P_{2}^{o} K_{L} v_{1}^{o}
$$

where $p_{2}^{\circ}$ is the solute vapor pressure and $v_{1}^{\circ}$ the stationary phase molar volume [6]. Results obtained in $3 \mathrm{MS}$ at $40^{\circ} \mathrm{C}$ can be read on Table 4, and compared with the results obtained at $25^{\circ} \mathrm{C}$ in FA [13] and in EG [14]. The smallest values are obtained when $3 \mathrm{MS}$ is the solvent; differences with EG and FA are very important, and cannot be explained by the temperature difference. This trend is in coincidence with the absence of surfactant self-aggregation processes in 3MS found by Evans et al. [3]. It is important to stress that if positive deviations from the ideal behavior depend mainly on solute-solvent c.e.d. differences, and if the solvents 
c.e.d.'s are correctly gauged by the $\sigma / v^{1 / 3}$ quotients, the values of the activity coefficients in $3 \mathrm{MS}$ should be intermediate between those in FA and EG.

Table 4

\section{Bulk liquid and gas-liquid interface activity coefficients of hydrocarbons in polar solvents}

\begin{tabular}{|c|c|c|c|c|c|c|}
\hline \multirow[b]{2}{*}{ SOLUTE } & \multicolumn{2}{|c|}{$\mathrm{FA}, 25^{\circ} \mathrm{C}$} & \multicolumn{2}{|c|}{$\mathrm{EG}, 25^{\circ} \mathrm{C}$} & \multicolumn{2}{|c|}{$3 \mathrm{MS}, 40^{\circ} \mathrm{C}$} \\
\hline & $\gamma_{2}^{b, \infty}$ & $\gamma_{2}^{s, \infty}$ & $\gamma_{2}^{b, \infty}$ & $\gamma_{2}^{s, \infty}$ & $\gamma_{2}^{b, \infty}$ & $\gamma_{2}^{s, \infty}$ \\
\hline n-Heptane & 2220 & 110 & 1020 & 29.6 & 277 & 26.7 \\
\hline$n-O c t a n e$ & 3880 & 163 & 1730 & 39.2 & 415 & 31.1 \\
\hline n-Nonane & 6410 & 230 & 2850 & 53.5 & 585 & 39.3 \\
\hline n-Decane & & & & & 650 & 51.1 \\
\hline $2,2,4$ trimethylpentane & 2280 & 134 & 1150 & 32.8 & 269 & 29.9 \\
\hline Methylcyclohexane & 914 & 79.1 & 542 & 21.5 & 130 & 15.7 \\
\hline Ethylcyclohexane & 1710 & 118 & 773 & 29.7 & 199 & 23.0 \\
\hline 1-Heptene & 1010 & 70.4 & 507 & 21.6 & 122 & 16.6 \\
\hline 1-Octene & 1850 & 103 & 914 & 28.6 & 191 & 21.6 \\
\hline 1-Nonene & & & & & 272 & 29.0 \\
\hline Benzene & 52.3 & 15.2 & 32.3 & 5.64 & 5.89 & 2.49 \\
\hline Toluene & 102 & 22.0 & 61.7 & 7.90 & 9.48 & 3.50 \\
\hline Ethylbenzene & 196 & 32.0 & 112 & 10.3 & 15.9 & 4.63 \\
\hline m-Xylene & 214 & 33.6 & 124 & 11.2 & 15.4 & 4.88 \\
\hline p-Xylene & 208 & 33.9 & 123 & 11.2 & 15.5 & 4.98 \\
\hline
\end{tabular}

Surface activity coefficients at infinite dilution, $\gamma_{2}^{\mathbf{s}, \infty}$, were calculated with the equation deduced by Eon and Guiochon [15] for a monolayer model:

$$
\gamma_{2}^{s, \infty}=\left[R T / p_{2}^{\circ}\left(K_{L} v_{1}^{\circ}+K_{A} a_{1}^{o}\right)\right] \exp \left[a_{2}^{\circ}\left(\sigma_{1}^{\circ}-\sigma_{2}^{\circ}\right) / R T\right]
$$

where $\sigma_{1}^{\circ}$ and $\sigma_{2}^{\circ}$ represent the stationary phase and the solute surface tensions in the pure state, respectively; $a_{1}^{\circ}$ and $a_{2}^{\circ}$ are the corresponding molar surface areas, approximated by the relation $a_{i}^{0}=12 N^{1 / 3}\left(v_{i}^{0}\right)^{2 / 3}$, where $N$ is Avogadro's constant. This last is a rough approximation, only valid for spherical molecules; a more exact calculation would demand to take into account not only the molecular shape but also to know how the molecule settles on the surface. The results obtained for adsorption on $3 \mathrm{MS}$ at $40^{\circ} \mathrm{C}$ have been gathered in Table 4 , together with the results taken from former papers for $\mathrm{FA}$ and $\mathrm{EG}$ at $25^{\circ} \mathrm{C}$ [16].

In contrast to the trends observed in Figure 2, points corresponding to hydrocarbons of different families fall on a common straight line in Figure 4, where logarithms of activity coefficients in the surface phase are plotted against the corresponding values in the bulk phase; the correlation coefficient is 0.997 , and a similar behavior is observed for the results in FA and in EG [16]. For systems with strong adsorption $K_{A} a_{1}^{\circ}>K_{L} v_{1}^{\circ}$, and from Eq. (5) and Eq. (6)

$$
K_{A} / K_{L} \cong\left(\gamma_{2}^{b, \infty} v_{1}^{o} / \gamma_{2}^{s, \infty} a_{1}^{o}\right) \exp \left[a_{2}^{o}\left(\sigma_{2}^{o}-\sigma_{1}^{o}\right) / R T\right]
$$


that indicates that the different trends displayed in both figures can be attributed to the very unlike surface tensions exhibited by hydrocarbons of different families in the pure state.

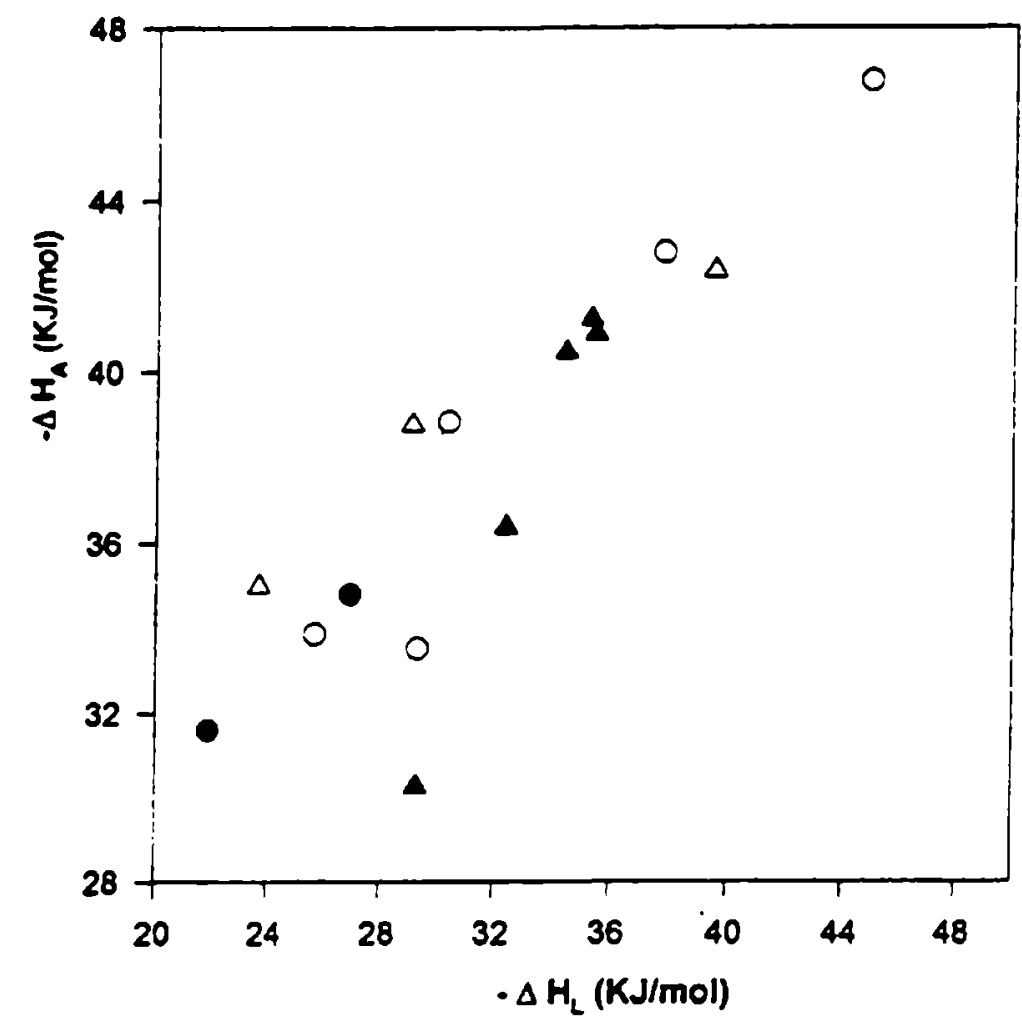

Fig. 3.- Relationship between adsorption and partition enthalpies. Symboks ss in Figure 2.

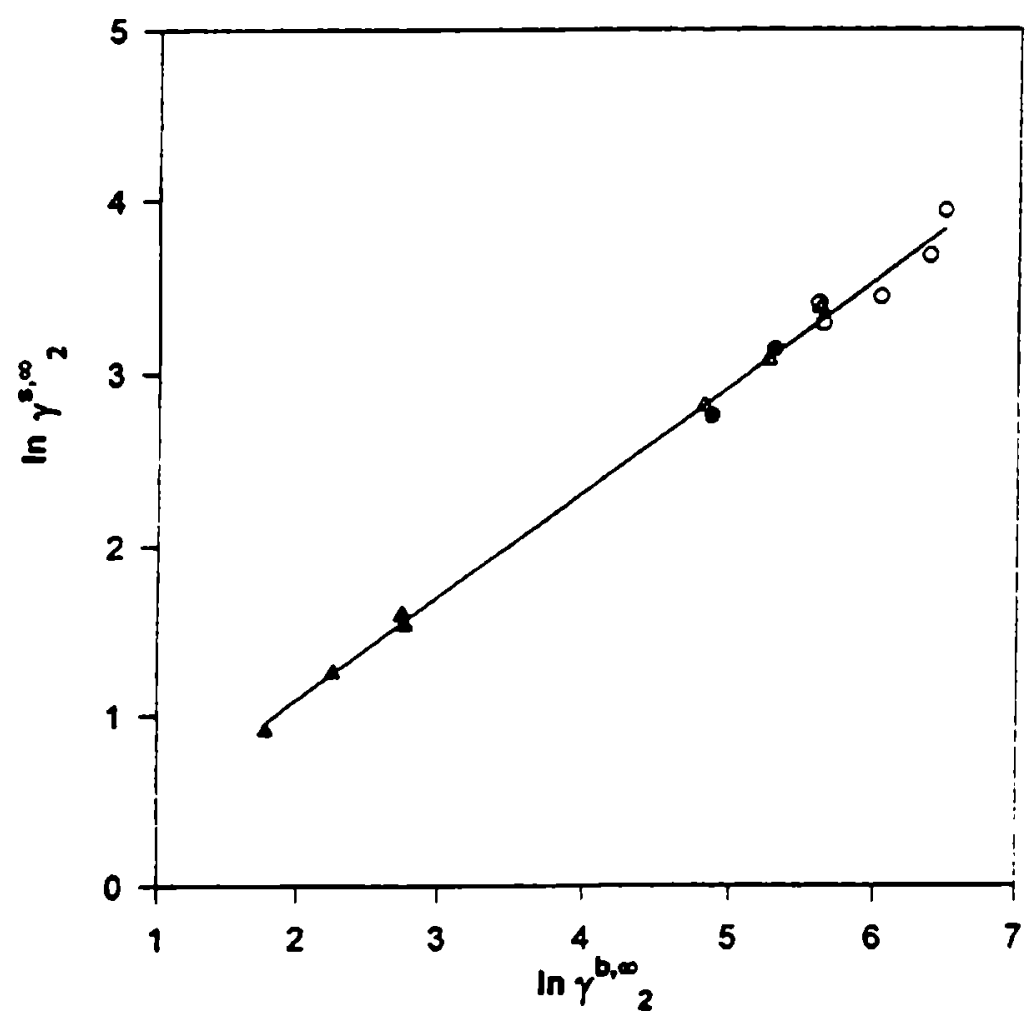

Fig. 4.- Relationship between gas-liquid interface and bulk liquid infinute dilution activity coefficients at $40^{\circ} \mathrm{C}$. Symbols as in Figure 2.

For all the studied systems surface activity coefficients are smaller than their bulk counterparts. This is the trend that could be expected: since the number of nearest neighbors is smaller at the surface than in bulk solution, nonideality effects are expected to be lower at the surface. However when the values obtained in both phases of the three solvents are compared it can be seen that the activity coefficients on the 3MS surface are larger than what could be predicted on the basis of the values of the activity coefficients in the bulk phase; alkanes surface activity coefficients in 3MS, for instance, are almost equal to those in EG, in spite of very large differences between the bulk activity coefficients in both solvents. These trends are 
made evident in Figure 5, where the quotients $\left(\gamma_{2}^{s_{1} \infty} / \gamma_{2}^{b, \infty}\right)$ in 3MS have been plotted against the corresponding quotients in FA or EG.

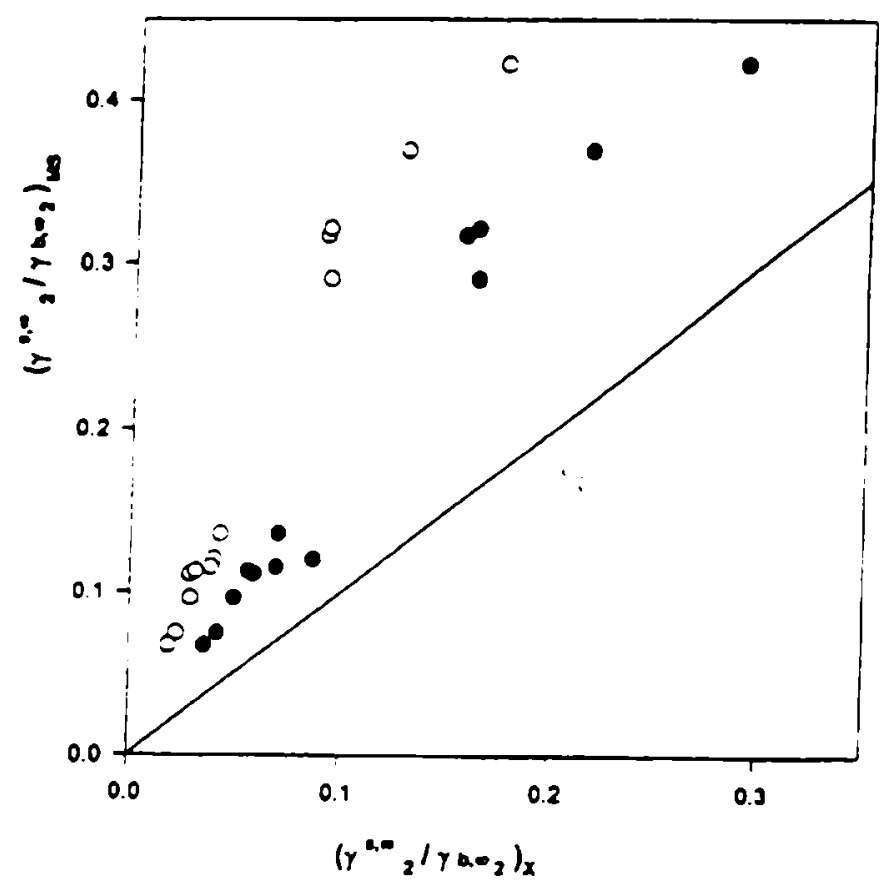

Fig. 5- Rebationship between the quotients $\left(\gamma_{2}^{5, \infty} / \gamma_{2}^{b, \infty}\right)$ in 3MS and in the stionary phase $X$ o: $X=E G ; 0: X=F A$

The line corresponds to equal values in both stationary phesea.

This figure tells us that the relationship between surface and bulk properties can be very different for different solvents, and about the unpredictability of surface properties exclusively on the basis of bulk properties and vice versa. This may be attributed to structural rearrangements of solvent molecules at the surface, through processes that can be very different in a given solvent than in another. From this point of view, the surface tension of $3 \mathrm{MS}$ can be the result of an intense dipoles orientation process at the liquid surface, that keeps very little relation with the random distribution in the bulk suggested by the value of its $g$ factor

In order to further test this possibility the dispersion contributions to the surface tension, $\sigma_{1}^{d}$, of FA, EG and 3MS were calculated by two methods:

I. The proposal of Hauxwell and Ottewill [17], as applied by Hartkopf [18] to gas chromatographic data: a plot of $K_{A} p_{2}^{\circ}$ against $\sigma_{2}^{\circ}$ for saturated hydrocarbons (alkanes or cycloalkanes) results in a straight line that intersects the abscissa at $\sigma=\sigma_{1}^{d}$.

II. By Dorris and Gray proposal (19), according to which

$$
\sigma_{1}^{d}=\left(\Delta G_{\mathrm{CH}_{2}} / 2 \mathrm{Na}_{\mathrm{CH}_{2}}\right)^{1 / 2} \sigma_{\mathrm{CH}_{2}}^{-1}
$$

where $\mathrm{N}$ is Avogadro number, $\mathrm{a}_{\mathrm{CH}_{2}}$ is the cross-sectional area of $-\mathrm{CH}_{2}$ groups $\left(0.06 \mathrm{~nm}^{2}\right)$, $\sigma_{\mathrm{CH}_{2}}$ is the surface free energy of a surface made up of only $-\mathrm{CH}_{2}$ - groups (35 dyn/cm, as calculated for poly(ethylene)), and $\Delta G_{\mathrm{Cr}_{2}}$ is given by

$$
\Delta G_{\mathrm{CH}_{2}}=R T \ln \left(K_{A, n+1} / K_{A, n}\right)
$$


where $K_{A n+1}$ and $K_{A n}$ are the adsorption coefficients for normal alkanes with $n+1$ and $n$ carbon atoms, respectively. The results have been gathered in Table 5 , that shows that both methods are only in a moderate agreement. Both methods indicate important polar contributions, $\sigma_{1}^{h}$, to the surface tension of 3MS (as calculated by the difference $\sigma_{1}^{h}=\sigma_{1}^{\circ}-\sigma_{1}^{d}$ ), not very different from those corresponding to FA and EG.

\section{Table 5}

Dispersion contributions to the surface tension of solvents calculated by two different methods

$\begin{array}{ccc}\text { SOLVENT } & \text { METHOD I } & \text { METHOD } \mathbf{H}^{\mathrm{b}} \\ \text { FA } & 29.6 & 28.8 \\ \text { EG } & 30.2 & 28.6 \\ \text { 3MS } & 28.3 & 32.0 \\ & \begin{array}{c}\text { Units: dyn/om } \\ \text { ' } \operatorname{Ref} 17 \text { and 18. }{ }^{\mathrm{b}} \text { Ref } 19\end{array}\end{array}$

These results reflect important differences between the surface (as given by $\sigma_{1}^{h}$ ) and the bulk (according to its Kirkwood $g$ factor) properties of 3MS. Under these circumstances the prediction of its c.e.d. through the quotient $\sigma / v^{1 / 3}$ can result in a serious overestimation, and this can be the origin of its incapacity for forming micelles and of the relatively small positive deviations from Raoult's law displayed by hydrocarbons.

\section{ACKNOWLEDGEMENTS}

This work was sponsored by CONICET (Consejo Nacional de Investigaciones Científicas y Técnicas de la Rep. Argentina) and by CICPBA (Comisión de Investigaciones Cientificas de la Prov. de Buenos Aires).

\section{REFERENCES}

[1] Lemire, RJ.; Sears, P. G.- J. Chem. Eng. Data, 22, 376 (1977).

[2] Gordon, J.E.- The Organic Chemistry of Electrolyte solutions. Wiley, New York (1975).

[3] Beesley, A.H.; Evans, D.F.; Laughlin, R.G.- J. Phys. Chem., 92, 791 (1988).

[4] Martire, D.E.-, In Progress in Gas Chromatography (J. H. Purnell, Ed.), Chap. 2. Wiley-Interscience, New York (1968).

[5] Conder, J.R; Locke, D.C.; Purnell, J.H.- J. Phys. Chem., 73, 700 (1969).

[6] Conder, J.P.; Young, C.L.- Physicochemical Measurement by Gas Chromatography, Chap. 11, Wiley, New York (1979).

[7] Castells, R.C.- J. Chromatogr., 111, 1 (1975).

[8] Vasil'eva, V.F.; Yashunskii, V.G.- J. Gen . Chem. USSR (Engl. Transl.) 32, 2845 (1962).

[9] Laub, R.J.; Pecsok, R.L.- Physicochemical Applications of Gas Chromatography. Wiley-Interscience, New York (1978).

[10] Martire, D.E.; Pecsok, R.L.; Purnell, J.H.- Trans. Faraday Soc, 61, 2496 (1965). 
[11] Castells, R.C.- J. Chromatogr., 350, 339 (1985).

[12] Meyer, E.F.- J. Chem. Educ, 57, 120 (1980).

[13] Castells, R.C.- An. Asoc. Quim. Argent., 64, 155 (1976).

[14] Arancibia, E.L.; Catoggio, J.A.- J. Chromatogr., 238, 281 (1982).

[15] Eon, C.; Guiochon, G.- J. Colloid Interface Sci, 45, 521 (1973).

[16] Castells, R.C.; Arancibia, E.L.; Nardillo, A.M.- J. Colloid Interface Sci, 90, 532 (1982).

[17] Hauxwell, F.; Ottewill, R.H.- J. Colloid Interface Sci, 34, 473 (1970).

[18] Hartkopf, A. J. Colloid Interface Sci, 40, 313 (1972).

[19] Dorris, C.M.; Gray, D.G.- J. Colloid Interface Sci., 77, 353 (1980) 